\title{
75. Reading from an Indexed Sequential File
}

In order to read from an Indexed Sequential File it is necessary to place the key for the record you want in the appropriate field before attempting to read. The program will then find the record which has that key field.

\section{Example}

The Environment Division and Data Division for this program are the same as for the example program in the previous lesson.

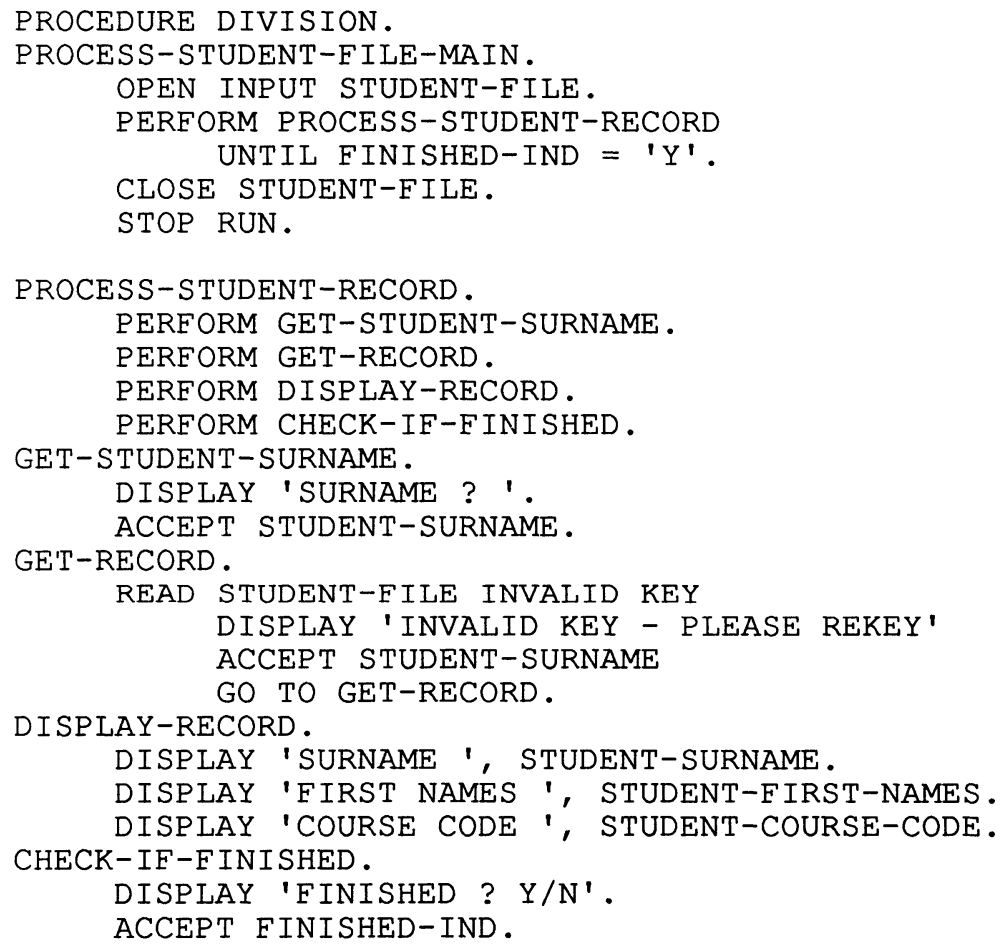

\section{Exercise}

Write a program which will allow the user to specify an employee by surname then retrieve and display all the data about him/her (use the file created in the previous exercise). 